\title{
ADAPTIVE SINGLE-POLE AUTORECLOSURE SCHEME BASED ON WAVELET TRANSFORM AND MULTILAYER PERCEPTRON
}

\author{
E. A. Frimpong, P. Y. Okyere and E. K. Anto \\ Department of Electrical and Electronic Engineering \\ Kwame Nkrumah University of Science and Technology, Kumasi, Ghana
}

\begin{abstract}
Adaptive autoreclosing is a fast emerging technology for improving power system marginal stability during faults. It avoids reclosing unto permanent faults and recloses unto transient faults only after the secondary arc has extinguished. The challenges that come with the application of the adaptive autoreclosing technology are enormous. To come to grips with these challenges, researchers have been proposing autoreclosure schemes which use artificial neural network $(A N N)$, the reason being that ANNs have in recent years clearly demonstrated their ability in solving some long standing problems in power systems where conventional techniques have difficulty. This paper proposes one such scheme for single-pole autoreclosure. The scheme uses multilayer perceptron artificial neural network which decides whether a fault is transient or permanent based on the percentage of energy in detailed coefficients of Daubechies db4 mother wavelet of the power system faulted voltage. In the case of transient faults, the neural network further determines the optimal reclosure time. A multilayer perceptron neural network was developed to suit the input signal adopted for the scheme and trained using the LevenbergMarquardt back-propagation technique. The scheme was simulated using the Electromagnetics Transient Programme (EMTP) and MATHLAB software. The results of the simulation show that the proposed ANN-based adaptive single-pole autoreclosure (AdSPAR) scheme is capable of distinguishing between permanent and transient faults and in the case of the latter, predict optimal reclosure times.
\end{abstract}

Keywords: Adaptive autoreclosure, Artificial neural networks, Autoreclosure, Signal processing, Stability, Wavelet transform

\section{INTRODUCTION}

The massive demand for electric power and difficulty in constructing new lines owing to cost and environmental pressures have led to the transmission of more power through existing transmission networks. These coupled with the high incidence of single-phase-to-ground faults threaten the stability of the power system (Aggarwal, 1998) and thus making the use of autoreclosure schemes imperative. Notwithstanding, unsuccessful reclosure in conventional autoreclosure schemes using a fixed dead 
time may aggravate potential damage to system and equipment (Fitton et al., 1996). Adaptive autoreclosures adapt reclosure times and therefore present advantages such as minimized unsuccessful reclosing, improvements in transient stability margins, high-speed response to sympathy trips and reduction in system and equipment shocks (Aggarwal et al., 1994; IEEE Committee Report, 1992).

Researchers, recognizing the numerous merits of the adaptive autoreclosure, have proposed a number of adaptive autoreclosure schemes. These include schemes which measure and compare the voltage of the tripped phase to that of the energized phases to initiate or prevent autoreclosing (Faried et al., 1998; Aggarwal et al., 1993), schemes which make use of various components of faulted voltage such as total harmonic distortion, $d c$ component and rms value to achieve successful autoreclosing (Park et al., 2004; Megahed et al., 2003; Kim et al., 2000; Ahn et al., 2001; Ahn et al., 2006) and schemes which employ high frequency current and voltage signals (Bo et al., 1997; Youyi et al.; 2001, Aggarwal et al.; 1997, Chen et al.; 2003). One significant demerit of the aforementioned schemes is that the many causes of faults and the interplay of several factors such as line configuration, fault position, fault point on wave, prefault loading, source parameters, and atmospheric conditions which influence the actual waveforms of the secondary arc voltage are likely to hinder their effectiveness (Aggarwal et al., 1994). They are also limited by their inability to cope with previously unencountered situations.

To overcome the above challenges, researchers are turning to ANNs which in recent years have clearly demonstrated their ability in solving some long standing problems in power systems where conventional techniques have difficulty. ANNs have the ability to learn from experience in the form of training and to recognize the hidden relationships that might exist in those training patterns. Patterns with noise superimposed on them may be recognized by a neural network that has been well trained (Al-hassawi et al., 2006). A number of ANN-based autoreclosure schemes use artificial neural networks such as Recurrent, Multilayer perceptron (MLP) and Radial basis function (RBF) (Fitton et al., 1996; Aggarwal et al., 1994; Zoric et al., 2000; Yu and Song, 1998a; 1998b; 1998c; ElHadidy et al., 2004; Chen et al., 2004; Lukowicz, 2004). With the exception of the recurrent-neural-network-based scheme (Lukowicz, 2004 ), the ANN-based schemes employ signal processing tools such as Fourier transform (Aggarwal et al., 1994), short-time fast Fourier transform (Fitton et al., 1996; Zoric et al., 2000), and wavelet transform ( $\mathrm{Yu}$ and Song, 1998a; 1998b; 1998c; El-Hadidy et al., 2004; Chen et al., 2004 ) to decompose voltage waveforms and extract vital features for adaptive autoreclosing. The signal processing is necessary to facilitate the decision making process of the ANN in the face of several factors given above that influence the faulted voltage waveform.

The application of neural network to adaptive autoreclosure scheme generally consists of four basic tasks (Aggarwal et al., 1994): (i) collecting or producing sets of sample of faulted voltage waveforms: (ii) preprocessing the data and extracting the useful features; (iii) choosing and building the most appropriate neural network; and (iv) using the processed sample data to train the neural network and then testing it by simulated fault transient data.

The adaptive single-pole ANN autoreclosure scheme presented in this paper employs Discrete Wavelet Transform (DWT) signal processing tool, which has been shown to be the most resilient to noise ( $\mathrm{Yu}$ and Song, 1998a; 1998b). An ANN architecture is also developed to suit the processed data. The scheme is simulated using the well proven and widely accepted Electro-Magnetics Transient Program (EMTP) and the MATLAB. The scheme is able to distinguish clearly between permanent and transient faults and in the case of the latter, predict optimal reclosure times at various fault points on wave and fault locations, indicating its robustness. 


\section{PROPOSED ADAPTIVE SINGLE-POLE} AUTORECLOSURE SCHEME

A block diagram of the proposed DWT, ANNbased AdSPAR scheme is shown in Fig. 1. The scheme is activated by a start logic when the circuit breaker is tripped. The DWT processes the signal from the Capacitor Voltage Transformer (CVT) and extracts the percentage of wave energy in detailed components from one cycle of voltage waveform for the neural network to determine whether the arc extinguishes or not. If not, the features of the next cycle are presented to the neural network again. This procedure is repeated until the neural network detects arc extinction in the case of transient fault or until after a certain preset time when the fault is deemed to be permanent. Once the fault is identified to be transient, a signal is sent to reclose the breakers. Otherwise, a signal is sent to trip the other two healthy phase breakers immediately and lock out the single-pole autoreclosure.

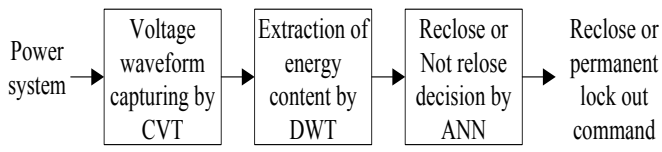

Fig. 1: Block diagram of proposed scheme

\section{SYSTEM COMPONENT MODEL AND SIMULATION}

A typical UK $400 \mathrm{kV}$ uncompensated, single circuit, transmission line commonly employed to develop and test adaptive autoreclosure schemes (Aggarwal et al., 1994; Yu and Song, 1998a; 1998b) is used for the study. The system is shown in Fig. 2. The frequency dependent parameters of the line were calculated via the inbuilt EMTP line constant program. The EMTP has no inbuilt transient arc model. The transient arc used for the study was modelled using the Transient Analysis of Control Systems (TACS) component of the EMTP based on the following arc equations given by Kizilcay et al., (1991):

$g t=G t-\Delta t-[G t-\Delta t-g t-\Delta t] e^{-\frac{\Delta t}{\tau}}$

$$
\begin{aligned}
& G=\frac{|i|}{\left(u_{0}+R|i|\right) l} \\
& \tau=\frac{\int_{t_{1}}^{t_{2}} \frac{|u|}{u_{0}+R|i| l} d t-\int_{t_{1}}^{t_{2}} d t-t_{2}-t_{1}}{\ln \left[g_{2} / g_{1}\right]}
\end{aligned}
$$

where $g$ is arc conductance in mhos; $G$ is stationary arc conductance in mhos; $i$ is arc current in $k A ; l$ is arc length in $\mathrm{cm} ; R$ is resistive component of the stationary arc characteristic per arc length in $m \Omega / \mathrm{cm} ; t$ is time in $m s ; D t$ is time step of digital simulation in $\mu s ; u$ is arc velocity in $\mathrm{cm} / \mathrm{ms} ; u_{0}$ is constant voltage parameter of the stationary arc characteristic per arc length in $V / \mathrm{cm}$, and $\tau$ is time constant $m s$.

A CVT was also included in the simulation. A $100-\Omega$ linear resistor was used to model permanent faults. Single phase-earth faults were simulated at various points along the line from the sending end. The fault point on wave was also varied. A sampling frequency of $6000 \mathrm{~Hz}$ was used.

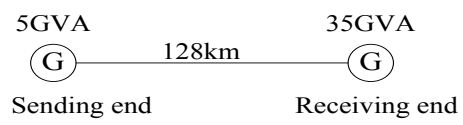

Fig. 2: $\quad$ Studied System

\section{Signal processing}

Faulted voltage waveform generated from the EMTP was converted into MATLAB files using a file converter. The waveform was then extracted every cycle for analysis.

Fault transients generated on a system contain a wide range of frequency components. It has been established from analysis that the most distinct characteristics of the waveforms are those associated with the variation of the frequency components over time (Fitton et al., 1996). It is also known from extensive studies that for each cycle, certain frequency bands can be used as potential features (Aggarwal et al., 1994). Thus the waveform extracted every cy- 
Table 1: Percentage energies of detailed coefficients for permanent and transient fault at $64 \mathrm{~km}$ at voltage-zero.

\begin{tabular}{|c|c|c|c|c|c|c|}
\hline \multirow{3}{*}{ Cycle No. } & \multicolumn{5}{|c|}{ Percentage energies of detailed coefficients } & \\
\hline & \multicolumn{4}{|c|}{ Permanent fault } & \multicolumn{2}{|c|}{ Transient fault } \\
\hline & d4 & d6 & d7 & d4 & d6 & d7 \\
\hline 1 & 0.0603 & 0.9101 & 2.0341 & 9.3580 & 15.5595 & 10.1315 \\
\hline 2 & 0.0038 & 3.0568 & 5.5958 & 0.1954 & 3.8284 & 3.7191 \\
\hline 3 & 0.0033 & 2.8221 & 5.2752 & 0.1997 & 3.5070 & 3.6241 \\
\hline 4 & 0.0034 & 2.7652 & 5.1297 & 0.2026 & 3.1246 & 3.8048 \\
\hline 5 & 0.0032 & 2.6950 & 5.0380 & 0.1650 & 2.5010 & 3.7349 \\
\hline 6 & 0.0032 & 2.6547 & 4.9442 & 0.1206 & 1.9797 & 3.6657 \\
\hline 7 & 0.0031 & 2.6076 & 4.8745 & 0.0685 & 1.4998 & 3.7830 \\
\hline 8 & 0.0031 & 2.5689 & 4.7965 & 0.0256 & 1.0186 & 3.8328 \\
\hline 9 & 0.0030 & 2.5316 & 4.7355 & 0.0402 & 0.6614 & 3.2092 \\
\hline 10 & 0.0030 & 2.4957 & 4.6684 & 0.0708 & 0.5108 & 2.5751 \\
\hline 11 & 0.0030 & 2.4638 & 4.6132 & 0.1023 & 0.5408 & 2.4923 \\
\hline 12 & 0.0029 & 2.4312 & 4.5548 & 0.1157 & 0.6861 & 2.7391 \\
\hline 13 & 0.0029 & 2.4027 & 4.5043 & 0.0568 & 1.0447 & 3.5118 \\
\hline 14 & 0.0029 & 2.3735 & 4.4527 & 0.0165 & 0.0504 & 6.8911 \\
\hline 15 & 0.0028 & 2.3476 & 4.4066 & 0.0058 & 1.1802 & 1.1959 \\
\hline 16 & 0.0028 & 2.3214 & 4.3608 & 0.0054 & 1.3284 & 1.4183 \\
\hline 17 & 0.0028 & 2.2978 & 4.3186 & 0.0053 & 1.2950 & 1.3848 \\
\hline 18 & 0.0028 & 2.2742 & 4.2776 & 0.0051 & 1.2632 & 1.3480 \\
\hline 19 & 0.0027 & 2.2525 & 4.2391 & 0.0050 & 1.2421 & 1.3220 \\
\hline
\end{tabular}

cle was decomposed using the Daubechies db4 mother wavelet in MATLAB into 9 frequency bands: $\quad 3000-1500 \mathrm{~Hz}, \quad 1500-750 \mathrm{~Hz}, \quad 750-$ $375 \mathrm{~Hz}, 375-187 \mathrm{~Hz}, \ldots .$. Then the wavelet energy also in MATLAB was used to extract the percentage of energy in the various bands to identify the most significant bands. Analysis of the results revealed that bands 4, 6 and 7 (that is detailed coefficients $\mathrm{d} 4, \mathrm{~d} 6$ and $\mathrm{d} 7 \mathrm{of} \mathrm{db} 4$ ) were the most significant for each cycle for decision making. Consequently, their percentage energies were used as inputs to the ANN. Table 1 shows the percentage energies of detailed coefficients for the case of permanent and transient faults at $64 \mathrm{~km}$ at voltage-zero.

\section{ANN architecture and training}

A three-layer feedforward-multilayer perceptron known to have fast decision making capability was developed for this study. The ANN, shown in Fig. 3 has three neurons in the input layer and 1 neuron in the output layer. The ANN has purelin and tansig as the transfer functions in the input and hidden layers, respectively. The number of neurons in the hidden layer was varied from 4 to 6 and the transfer function of the output layer varied between purelin and tansig to determine the best ANN architecture. Best ANN responses were obtained from the neural network with 6 neurons in the hidden layer and tansig transfer functions in the output neuron. Training of the networks was carried out using the Levenberg-Marquardt back-propagation technique for its fast and accurate training capabilities (Neural Network Toolbox for use with MATLAB, 1998). The neural network was trained with a set of inputoutput pairs. The inputs were the percentage of energies of the detailed coefficients and the outputs were ' 1 ' and ' 0 '. 1 indicates the persistence of a fault arc and 0 , the extinction of a transient fault arc. 


\section{Frimpong et al.}

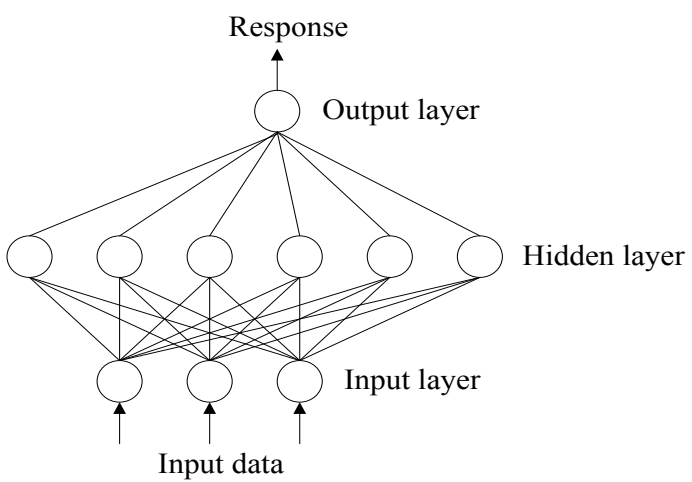

Fig. 3: Neural network architecture

\section{RESULTS AND DISCUSSION}

To test the robustness of the proposed scheme, both permanent and transient faults were simulated at various locations and for each location at voltage-zero and voltage-maximum. A credible AdSPAR scheme must be based on realistic transient fault arc model. Figures 4 and 5 show voltage waveforms of transient faults at $64 \mathrm{~km}$ voltage-maximum and $120 \mathrm{~km}$ voltage- maximum respectively. The waveforms, depicting the characteristics of a true faulted voltage waveform (Kizilcay et al., 1991), show that the TACS-built transient arc model was realistic. Voltage waveform of a permanent fault at $64 \mathrm{~km}$ voltage-maximum is shown in Fig. 6.

For the transient case shown in Fig. 4, at the point marked $\mathbf{A}$ on the waveform, a fault develops on the line and there is a subsequent reduction in the voltage. The protection system detects the fault and opens the circuit breakers at point B. A secondary arc is then established and this can be seen extinguishing and restriking, by the characteristic high frequency components in the waveform. Finally, the arc extinguishes completely at point $\mathbf{C}$. There remains a small system frequency voltage sinusoid component on the line after point $\mathbf{C}$, which is due to electrostatic coupling between the faulted phase and the two healthy phases. After point $\mathrm{C}$ there is a $\mathrm{DC}$ offset on the line which is due to the stored charge at the point on wave at which the arc finally extinguished. In practice, this primary voltage DC offset is attenuated by

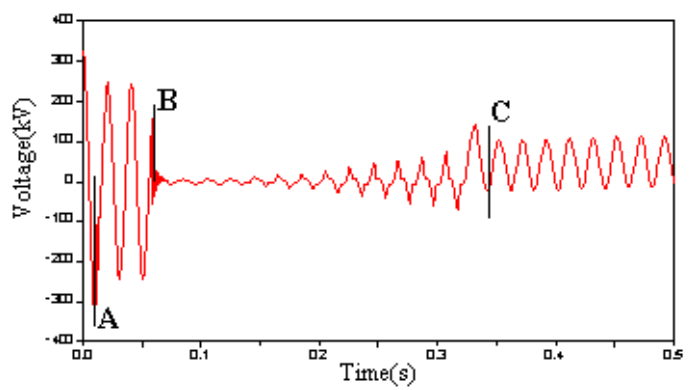

Fig. 4: Transient fault at $64 \mathrm{~km}$ voltagemaximum

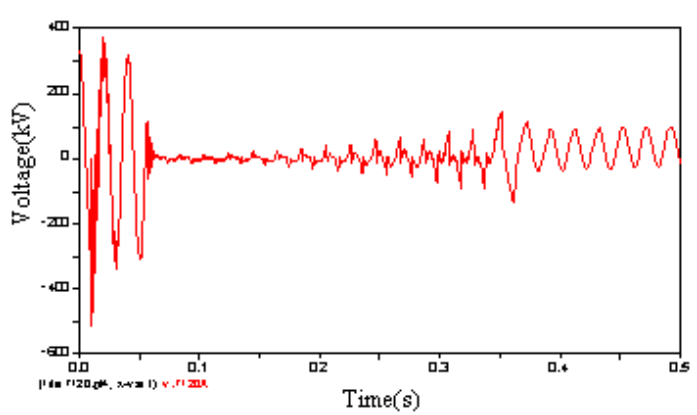

Fig. 5: Transient fault at $120 \mathrm{~km}$ voltagemaximum

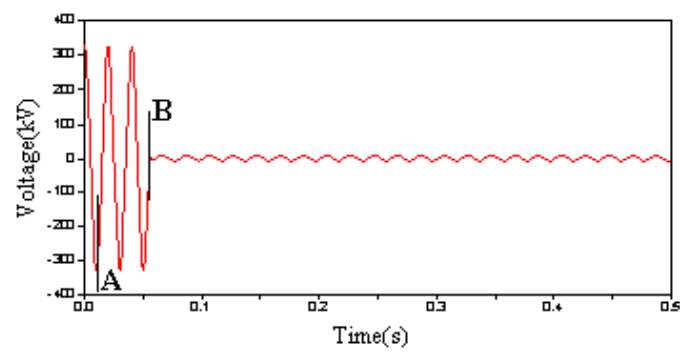

Fig. 6: Permanent fault at $64 \mathrm{~km}$ voltagemaximum

the effect of the CVT, but a lower than fundamental frequency surge can be seen. A similar explanation is offered to the transient case shown in Fig. 5. Additionally, the high frequency distortions on the waveform in Fig. 5 are due to the limitation of the EMTP programme in simulating faults close to the end of the line. For the permanent fault voltage waveform shown in Fig. 6, the fault occurs at point $\mathbf{A}$ and the protection trips the circuit breakers at 
point B. After the circuit breakers have tripped there is a small system frequency voltage induced onto the tripped phase. The magnitude of this voltage depends on the fault impedance and how well the other two healthy phases are coupled to the faulted phase.

Tables 2 and 3 show the performance of this neural network for permanent and transient faults at $64 \mathrm{~km}$ voltage-zero and $120 \mathrm{~km}$ voltagezero which are representative of the results obtained.

A comparison between the desired and obtained ANN outputs of Tables 2 and 3 clearly shows that the results attained are satisfactory; ANN responses in most cases are very close to the ideal outputs of either ' 0 ' or ' 1 '. The negative values of some of the neural network responses are satisfactory since these values are close to the desired value of ' 0 '.

A change from near ' 1 ' to near ' 0 ' signifies the extinction of a transient fault arc and no change indicates the persistence of a permanent fault.
Additionally, in the case of the transient fault, the time at which the change occurs, gives the precise arc extinction time. Since there is always a deviation of the ANN output around ' 0 ' and ' 1 ', small threshold levels will have to be set.

Figures 7 and 8 show the time response of the ANN to permanent and transient faults at 64 $\mathrm{km}$ at voltage-zero. It can be seen from Fig. 7 that for the permanent fault, no change in value from ' 1 ' to ' 0 ' occurs throughout the period. However, in the case of the transient fault in Fig. 8, a change from ' 1 ' to ' 0 ' occurs at about $0.34 \mathrm{~s}$. This time corresponds to arc extinction.

\section{CONCLUSION}

An adaptive single-pole autoreclosure scheme based on wavelet transform analysis and multilayer perceptron ANN is developed in this paper. The proposed scheme uses the percentage of energy of detailed coefficients of Daubechies db4 mother wavelet to make autoreclosure decisions. The results show that location of faults

Table 2: ANN response to permanent and transient faults at $64 \mathrm{~km}$ voltage-zero

\begin{tabular}{ccccc}
\hline \multirow{2}{*}{ Cycle No. } & \multicolumn{2}{c}{ Permanent fault } & \multicolumn{2}{c}{ Transient fault } \\
\cline { 2 - 5 } & ANN response & Desired response & ANN response & Desired response \\
\hline 1 & 0.9912 & 1 & 0.9992 & 1 \\
2 & 0.9989 & 1 & 0.9974 & 1 \\
3 & 0.9989 & 1 & 0.9977 & 1 \\
4 & 0.9989 & 1 & 0.9754 & 1 \\
5 & 0.9989 & 1 & 0.9490 & 1 \\
6 & 0.9989 & 1 & 0.9982 & 1 \\
7 & 0.9989 & 1 & 0.9991 & 1 \\
8 & 0.9989 & 1 & 0.9975 & 1 \\
9 & 0.9989 & 1 & 0.9982 & 1 \\
10 & 0.9989 & 1 & 0.9990 & 1 \\
11 & 0.9989 & 1 & 0.9992 & 1 \\
12 & 0.9989 & 1 & 0.9993 & 1 \\
13 & 0.9989 & 1 & 0.9988 & 0 \\
14 & 0.9989 & 1 & 0.1289 & 0 \\
15 & 0.9989 & 1 & -0.0312 & 0 \\
16 & 0.9989 & 1 & -0.00054 & 0 \\
17 & 0.9988 & 1 & 0.0018 & 0 \\
18 & 0.9988 & 1 & 0.00071 & -0.0011 \\
19 & 0.9988 & 1 & & 1 \\
\hline
\end{tabular}


108 Frimpong et al.

Table 3: ANN response to permanent and transient faults at $120 \mathrm{~km}$ voltage-zero

\begin{tabular}{ccccc}
\hline \multirow{2}{*}{$\begin{array}{c}\text { Cycle } \\
\text { No. }\end{array}$} & \multicolumn{2}{c}{ Permanent fault } & \multicolumn{2}{c}{ Transient fault } \\
\cline { 2 - 5 } ANN response & $\begin{array}{c}\text { Desired } \\
\text { response }\end{array}$ & $\begin{array}{c}\text { ANN } \\
\text { response }\end{array}$ & $\begin{array}{c}\text { Desired } \\
\text { Response }\end{array}$ \\
\hline 1 & 0.9914 & 1 & 0.9992 & 1 \\
2 & 0.9989 & 1 & 0.9990 & 1 \\
3 & 0.9989 & 1 & 0.9958 & 1 \\
4 & 0.9989 & 1 & 0.8286 & 1 \\
5 & 0.9989 & 1 & 0.9990 & 1 \\
6 & 0.9989 & 1 & 0.9992 & 1 \\
7 & 0.9989 & 1 & 0.9996 & 1 \\
8 & 0.9989 & 1 & 0.7367 & 1 \\
9 & 0.9989 & 1 & 0.9825 & 1 \\
10 & 0.9989 & 1 & 0.9992 & 1 \\
11 & 0.9989 & 1 & 0.9992 & 1 \\
12 & 0.9989 & 1 & 0.9995 & 1 \\
13 & 0.9989 & 1 & 0.9939 & 1 \\
14 & 0.9988 & 1 & 0.9990 & 0 \\
15 & 0.9988 & 1 & -0.0030 & 0 \\
16 & 0.9988 & 1 & 0.0165 & 0 \\
17 & 0.9988 & 1 & -0.0027 & 0 \\
18 & 0.9988 & 1 & 0.00041 & -0.2267 \\
19 & 0.9988 & 1 & &
\end{tabular}

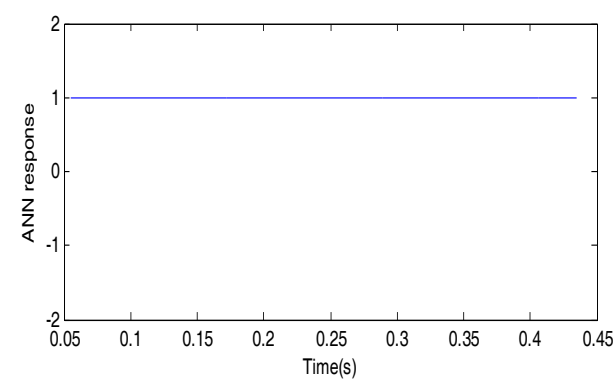

Fig. 7: ANN time response to a permanent fault at $64 \mathrm{~km}$ voltage-zero

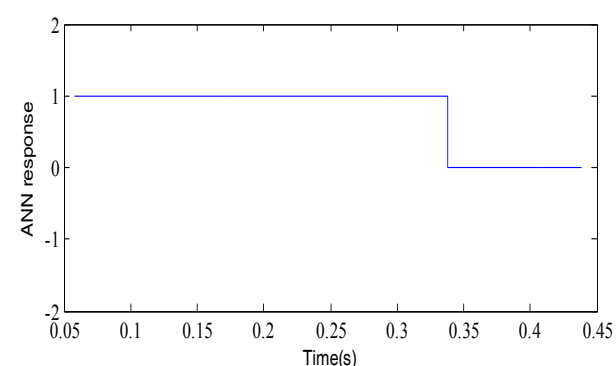

Fig. 8: ANN time response to a transient fault at $64 \mathrm{~km}$ voltage-zero and fault point on wave, some of the factors that influence faulted voltage waveform, have no effect on the ability of the scheme to distinguish between permanent and transient faults and to predict optimal reclosure times of the latter.

\section{REFERENCES}

Aggarwal, R. K., Johns, A. T. and Song, Y. H. (1993). Adaptive Single-Pole Autoreclosure Scheme Based on Defining and Identifying Fault Induced Voltage Waveform Patterns, IEEE/NUTA Athens Power Tech Conference, Athens Greece, IEEE, 1: 411416.

Aggarwal, R. K., Johns, A. T., Song, Y. H., Dunn, R. W. and Fitton, D. S. (1994): Neural-Network Based Adaptive Single-Pole Autoreclosure Technique for EHV Transmission Systems, IEE Porceedings on Generation, Transmission and Distribribution, 141(2): 155-160. 
Aggarwal, R. K., Bo, Z. Q. and Johns, A. T. (1997), A Novel Technique to Distinguish Between Transient and Permanent Faults Based on the Detection of Current Transients, Proceedings of the 4th International Conference on Advances in Power System Control, Operation and Management, APSCOM-97, Hong Kong, 11 - 14 November, IEEE, 216-220.

Aggarwal, R. K. (1998). Experience with Advance Adaptive Auto-Control Techniques for EHV Transmission Systems, IEE Colloquium on HV Measurements, Condition Monitoring and Associated Database Handling Strategies, 6/1-6/3.

Ahn, S. P., Kim, C. H., Aggarwal, R. K. and Johns, A. T. (2001). An Alternative Approach to Adaptive Single Pole AutoReclosing in High Voltage Transmission Systems Based on Variable Dead Time Control, IEEE Transactions on Power Delivery, 16(4): 676-686.

Ahn, S. P., Kim, C. H. and Aggarwal, R. K. (2006). Correction to An Alternative Approach to Adaptive Single Pole AutoReclosing in High Voltage Transmission Systems Based on Variable Dead Time Control, IEEE Transactions on Power Delivery, 21(1): 546.

Al-hassawi, W. M., Abbasi, N. H. and Mansour, M. (1996). A Neural-Network-Based Approach for Fault Classification and Faulted Phase Selection, Canadian Conference on Electrical and Computer Engineering, Canada, 26 - 29 May, IEEE, 384387.

Bo, Z. Q., Aggarwal, R. K., Johns, A. T., Zhang, B. H. and Ge, Y. Z. (1997). New Concept in Transmission Line Reclosure using High-Frequency Fault Transients, IEE Proceedings on Generation, Transmission and Distribution, 144(4): 351-356.

Chen, Z., Zhang, B. H., Bo, Z. Q. and Redfern, M. A. (2003). Adaptive Optimal Reclosure Based on Analysis of Fault Current Tran- sients, Power Engineering Society General Meeting, 2003, IEEE, 4: 2118-2121.

Chen, S., Liu, Y., and Xu, Z. (2004). Intelligent On-line Capturing Method for Optimal Time of Automatic Reclosing Transient Fault, Fifth World Congress on Intelligent Control and Automation, IEEE, 6: 50845086.

Demuth, H., Beale, M. and Hagan, M. (1998). Neural Network Toolbox for use with MATLAB, Users Guide, Version 3, 1-2, 536.

El-Hadidy, M. A., Moustafa, D. H. and Attia, A. S. (2004). Using Neuro-Wavelet Technique for Adaptive Single Phase Autoreclosure of Transmission Lines, IEEE Universities Power Engineering Conference, 2: 684-688.

Faried, S. O., Billinton, R. and Aboreshaid, S. (1998). Effect of Adaptive Single-Pole Reclosing on the Stochastic Behaviour of Turbine-Generator Shaft Torsional Torques, IEEE Transactions on Energy Conversion, 13(2): 133-139.

Fitton, D. S., Dunn, R. W., Aggarwal, R. K., Johns, A. T., and Bennet, A. (1996). Design and Implementation of an Adaptive Single Pole Autoreclosure Technique for Transmission Lines using Artificial Neural Networks, IEEE Transaction on Power Delivery, 11(2): 748-756.

IEEE Committee Report (1992). Single Phase Tripping and Auto Reclosing of Transmission Lines, IEEE Transactions on Power Delivery, 7(1): 182-184.

Kim, C. H., Ahn, S. P., Aggarwal, R. K. and Johns, A. T. (2000). A Novel Concept in Adaptive Single-Pole Auto-Reclosure as applied to High Voltage Transmission Systems, Proceedings of the 5th International Conference on Advances in Power System Control, Operation and Management, IEEE, 2: 380-384. 


\section{Frimpong et al.}

Kizilcay, M., Pniok, T. (1991): Digital Simulation of Fault Arcs in Power Systems, European Transaction on Electrical Power, 1: 55-59.

Lukowicz, M. (2004). A New Scheme for Single-Pole Autoreclosure Based on Recurrent ANNs, Eighth IEE International Conference on Developments in Power System Protection, 2004, IEEE, 2: 591-594.

Megahed, A. I., Jabr, H. M., Abouelenin, F. M. and El-Bakry, M. A. (2003). Development of an Adaptive Single-Pole AutoReclosure Scheme for Alexandria HV Transmission System, Transmission and Distribution Conference and Exposition, 2003 IEEE PES, Dallas, Texas, 1: 309314.

Park, J. B., Radojevic', Z. M. and Shin, J. R. (2004). A Numerical Algorithm for Adaptive Reclosing based on the Calculation of the Faulted Phase Voltage Total Harmonic Distortion Factor, IEEE Power Engineering Society General Meeting, 1: 94-98.

Youyi, L., Xinzhou, D., Bo, Z. Q., Chin, N. F. and Yaozhong, G. (2001). Adaptive Reclosure using High Frequency Fault Transients, IEE 7th International Conference on Developments in Power Systems Protection, IEEE, 375-378.
Yu, I. K. and Song, Y. H. (1998a). Development of novel adaptive single-pole autoreclosure schemes for extra high voltage transmission systems using wavelet transform analysis, Electric power systems research, 47(1): 11-19.

Yu, I. K. and Song, Y. H. (1998b). Wavelet Analysis and Neural Network Based Single -Pole Autoreclosure Scheme for EHV Transmission Lines, International Journal of Electrical Power \& Energy Systems, 20 (7): 465-474.

Yu, I. K. and Song, Y. H. (1998c). Wavelet Transform and Neural Network Approach to Developing Adaptive Single-Pole Autoreclosing Schemes for EHV Transmission Systems, IEEE Power Engineering Review, 62-64.

Zoric, K. J., Jejina, N. D. and Djuric, M. B. (2000). Secondary Arc Faults Detection and Determine Arc Extinction Time on Overhead Lines Using Neural Networks, Electric Machines and Power Systems, 28 (1): 79-85. 